\title{
РЕЦЕПЦИЯ ИДЕЙ ПАУЛЯ ТИЛЛИХА В СОВРЕМЕННОЙ ФИЛОСОФСКО-РЕЛИГИОЗНОЙ МЫСЛИ
}

Резюме. Широко известно, что наследие Пауля Тиллиха продолжало оказывать влияние на философские и религиозные движения в XX веке. Поскольку его работа и влияние были столь решающими по своей методологии и столь всеобъемлющими по своему содержанию, мы продолжаем встречать его в секулярном богословии Х. Кокса, богословии «Смерти Бога» У. Хамильтона, Дж. Робинсона и Т. Дж. Альтизера, феминистическом богословии М. Дейли и Р. Рэдфорд Рутер, богословии освобождения М. Л. Кинга и Г. Гутьерреса, богословии надежды Юргена Мольтманна и Вольфхарта Панненберга, христианской апологетике XX века, религиоведении, праве, политике и межрелигиозном диалоге.

Ключевые слова: Пауль Тиллих, влияние, теология, мысль.

Данканіч А.С., Дніпровський національний університет ім. Олеся Гончара, е-mail: artem_ dankanich@yahoo.com

Рецепція ідей Пауля Тілліха в сучасній реліхійно-філософській думці

Резюме. Добре відомо, щуо спадок Пауля Тілліха продовжував справляти вплив на філософські та релігійні рухи в ХХ столітті. Оскільки його робота та вплив були особливо вирішальними за своєю методологією і всеохоплюючими за своїм змістом, ми продовжуємо зустрічати його в секулярній теології Г. Кокса, теологї «Смерті Бога» В. Гамільтона, Дж. Робінсона та Т. Дж. Альтіцера, феміністичній теології М. Дейлі та Р. Редфорд Рутер, теології звільнення М. Л. Кінга і Г. Гутьєрреса, теологї надї Юргена Мольтмана і Вольфхарта Панненберга, християнській апологетиці ХХ століття, релігієзнавстві, праві, політиці та межрелігійному діалозі.

Ключові слова: Пауль Тілліх, вплив, теологія, думка.

Dankanich A.S., Oles Honchar Dnipro National University, e-mail:artem_dankanich@yahoo.com Paul Tillich's ideas reception in modern religion and philosophical thought

Abstract. It is widely known that Paul Tillich's legacy has had continuing influence on philosophical and religion movements in XX century. Since his work and influence was both so decisive in its methodology and so comprehensive in its content, we continue to meet it in secular theology of H.Cox, "Death of God» theology of W.Hamilton, J.Robinson and T. J. Altizer, Feminist theology of M.Daly and R.Radford Ruether, Liberation theology of M.L.King and G.Gutiérrez, theology of Hope of Jürgen Moltmann and Wolfhart Pannenberg, chrisitan apologetics of XX century, religion studies, law, politics, and inter-religious dialogue.

Keywords: Paul Tillich, influence, theology, thought.

Осмысление влияния П.Тиллиха философии, теологов, культурологов и на современную западноевропейскую религиоведов. Исследователи истории философию и религиозную мысль давно теологии и религиозной мысли ХХ в., С. находится в области исследовательского Гренц и Р.Олсон, оценивая роль П.Тиллиха интереса западныхи отечественныхисториков в современной эпохе отмечают: «Еще при 
«Філософія та політологія в контексті сучасної культури», 2018, Т.10. №1-2 (22)

жизни представители светской культуры называли Тиллиха одним из величайших умов христианского богословия. Немногие богословы пользовались таким признанием и почетом у политиков, членов правительств, руководства самых разных университетов и фондов. Исключением не стали даже средства массовой информации, о чем свидетельствует появление его фотографии на обложке журнала «Тайм» от 16 марта 1959 года» [1, c.165]. Популярность мыслителя во многом объясняется тем, что он был активно вовлечен в общественные проблемы Германии и США, а своей главной задачей видел создание универсальной христианской теологии культуры.

Стоит отметить, что деятельность П.Тиллиха генетически, идейно и тематически была связана с движением диалектической теологии первой половины $\mathrm{XX}$ ст. Именно в тесном сотрудничестве и полемике $\mathrm{c}$ виднейшими представителями этого течения - К.Бартом, Р.Бультманом, а позже и Д.Бонхеффером, сформировалась ключевая задача мыслителя - интерпретация христианской традиции в терминах секулярной культуры XX столетия.

C точки зрения автора настоящего исследования именно проблема создания «безрелигиозногохристианства», эксплицитно выступавшая в проектах «демифологизации» Р.Бультмана, «неоортодоксии» К.Барта и учения Д.Бонхеффера, выступила в качестве контекста формирования экзистенциально-герменевтической концепции П.Тиллиха. Благодаря П.Тиллиху и его решению этой проблемы, указанная тема нашла многочисленные отклики и резонанс в последующих религиозно-философских учениях.

Учение П.Тиллиха в западной литературе оценивается как через призму теологической, так и философской традиции. С именем мыслителя связывают возрождение либеральной протестантской мысли в XX веке. Именно П.Тиллих является создателем неолиберальной протестантской теологии.

Возрождение либерализма в XX веке, - пишут С.Гренц и Р.Олсон, - имело определенную ценность. П. Тиллих, обращают внимание теологи, напомнил о том, что Божье Слово «приходит в мир не по чьей-то прихоти, а в ответ на один из фундаментальных вопросов, которые ставит перед нами окружающий мир и наше собственное существование». Кроме того, он красноречиво сформулировал проблему, над решением которой работали богословы 60-х годов [1, с.475].

С точки зрения Д.Келси, принципиальной задачей П.Тиллиха было придание «христианству понятного характера для религиозно скептически настроенных людей. Мыслитель, как считает исследователь, был чрезвычайно эффективным в этой роли [9, c.62] .

П.Тиллих, обращает внимание Д.Келси, имеет продолжающееся влияние при обсуждении ряда теологических проблем. Исследователь выделяет ряд ключевых инверсий рецепции учения П.Тиллиха. Во-первых, показывает Д.Келси, философ придал новое звучание понятию религии и религиозности, широко понимаемой как «предельный интерес». Именно П.Тиллих ввел в английский язык новую дефиницию религии, которая даже укоренилась в американском праве. Во-вторых, мыслитель разработал теорию символов и религиозных символов, которые, как и в случае дефениции религии, имеют во многом схожее продолжающееся влияние. Теория религии П.Тиллиха, обращает внимание исследователь, находится в поле постоянных теологических дискуссий, где, с одной стороны, она занимает влиятельное положение при теоретическом осмыслении взаимоотношений между религией и изобразительным искусством, с другой, религией и литературой. В-третьих, теория П.Тиллиха продолжает формировать богословскую рефлексию феномена религиозного плюрализма и вопрос взаимоотношения между основными мировыми религиями $[9$, с.7273].

Нами выделено несколько ключевых направлений в философии и теологии 
XX ст., в рамках которых особенно ярко эксплицировались отдельные положения экзистенциально -герменевтической концепции П.Тиллиха. К таковым стоит отнести «Секулярное богословие», «Теологию «Смерти Бога», «Процесс-теологию», «Теологию Освобождения», «Процесстеологию».

Главным популяризатором идей и учения П.Тиллиха после его смерти был епископ англиканской церкви, теолог, библеист и философ Д.Робинсон. В работе «Быть честным перед Богом» Д.Робинсон подробно анализировал концепции Р.Бультмана, Д.Бонхеффера и П.Тиллиха, отмечая: «... может показаться, что теологические проблемы, выдвигаемые этими тремя авторами, весьма далеки от повседневной жизни простого человека. Но в важности этих вопросов меня убеждает не только тот живой отклик, который они вызывают во мне самом, но и то, что при всей своей очевидной сложности и укорененности в немецком складе ума они явно обращены не просто к более широкому образованному кругу, чем круг профессиональных теологов. Эти проблемы затрагивают и нецерковные массы нынешней урбанизированной и индустриальной цивилизации. П.Тиллих, - пишет епископ, - один из немногих теологов, которым удалось вырваться за пределы того, что сам он в другой связи называет «теологическим кругом» [11, с.18]. Анализируя проблему «Конца Теизма», Д.Робинсон отмечал, что именно П.Тиллиху принадлежит её проницательное и глубокое осмысление и в особенности при обсуждении супранатуралистичекого характера христианской традиции [11, c.21]. Как отмечает С.Гренц и Р.Олсон, в своей книге Д.Робинсон свел воедино различные направления современной мысли. Три учения имели особое значение: П.Тиллиха, Д.Бонхеффера и Р.Бультмана. П.Тиллих сформулировал проблему Бога с философской точки зрения. Р. Бультман поднял вопрос библейской интерпретации (с учетом использования в Библии мифов), который он решил, предложив программу демифологизации. Внимание

Д.Бонхёффера было приковано к теме Бога, Христа и природы церкви. Каждый из этих мыслителей по-своему подвергал сомнению традиционное понимание трансцендентности, в котором Бог представал как существо, запредельное этому миру. Используя различную терминологию, все они отвергли прежние образы веры как мифологические (Бультман), сверхъестественные (Тиллих) или религиозные (Бонхеффер). Вслед за ними Д.Робинсон тоже называл такого рода символизм устаревшим и считал его камнем преткновения для веры [1, с.243] .

Тиллиховская концепция Бога оказывала значительное влияние практически на все теологические движения XX в. Так, Дж.Ш.Спонг отмечал огромное значение тиллиховского пересмотра классического теизма и выражения его в формуле «Бог превыше Бога теизма» [12, с.73]. Восприняв тиллиховскую критику теизма христианской традиции, исследователь пишет: «Этот Бог является источником жизни, источником любви, основой бытия. Теистический Бог вчерашнего дня есть символом сущности, бытие жизни, в котором мы живём. Бог есть Бытие, говорим мы, и мы поклоняемся этому Богу» [12, с.73] .

С точки зрения Д.Гунсона, П.Тиллих, пожалуй, главный современный пионер «не-реалистической», гуманистической, рациональной светской теологии. Его теология, как показывает исследователь, ортодоксальна в том смысле, что он придерживается традиционных тем Откровения: Бога как Творца и Искупителя, греха, зла и спасения, Христа и его спасительной смерти и воскресения (во Христе «вечное единение Бога и человека стало исторической реальностью), Духа Святого, Царства Божия, церкви и вечной жизни. Особенностью П.Тиллиха, с точки зрения исследователя, выступает его неортодоксальность ( для многих традиционалистов, выступающая инославной и еретической), которая начинается с антропологии. Язык Священного 
«Філософія та політологія в контексті сучасної культури», 2018, Т.10. №1-2 (22)

Писания и теологии является символическим и не относится к объективным реалиям, включая понятие Бога. П.Тиллих, с точки зрения Д.Гунсона, не отрицал центральные доктрины христианства, но пытался переформулировать их в согласии с разумом и знанием $[7$, c.116] .

Известный исследователь истории религии К.Армстронг писала: «Пауль Тиллих (1868-1965 гг.) не сомневался, что Богличность традиционного для Запада теизма должен исчезнуть. С другой стороны, Тиллих верил, что вера людям необходима. Одной из сторон человеческой жизни является глубокая неискоренимая тревога, поскольку она не является неврозом и от нее не избавиться психотерапевтическими приемами. Мы постоянно боимся потерять самое дорогое и, наблюдая за необратимым разложением собственного тела, испытываем ужас перед неминуемой смертью» [4, с.487488]. К.Армстронг показывает, что П.Тиллих соглашался с Ф. Ницше в том, что касалось критики Бога, наделенного личностью. Именно посредством ницшеанской критики Бога, провозглашенной в формуле «Бог умер», П.Тиллих, как показывает исследователь пришел к понимаю того, что «Бог превыше Бога теизма».

Уже в 60-ые годы У.Гамильтон и Т.Альтицер создали движение, названное «Теология Смерти Бога», подпитываемое различными философскими и религиозными традициями и учениями, главным из которых выступало учение П.Тиллиха. С.Гренц и Р.Олсон отмечают, что У.Гамильтон при построении собственного проекта «Теологии «Смерти Бога» опирался на идеи Ф.Ницше, А.Камю и П.Тиллиха [1, с.237]. Т.Альтицер, как показывают С.Гренц и Р.Олсон, испытывал неизгладимое влияние Д.Бонхеффера и П.Тиллиха. Именно мыслителю Т.Альтицер и У.Гамильтон посвятили свою работу «Радикальная теология и смерть Бога». О значимости для «Теологии Смерти Бога» учения П.Тиллиха свидетельствует тот факт, что Т.Альтицер назвал мыслителя «отцом современной радикальной теологии».

Влияние П.Тиллиха особо заметно в «Теологии освобождения». Так, один из лидеров этого движения, протестантский теолог и философ Х.Кокс пишет: «Наше утверждение о том, что секулярный человек - прагматик и профан, заставляет еще раз задуматься о методах двух известнейших теологов-систематиков, которые горячо стремились сказать нечто важное современному человеку. Пауль Тиллих и Карл Барт, каждый по-своему, приложили страстные усилия к тому, чтобы прорваться сквозь секулярность современного человека и донести до него библейскую Весть. Тиллих смело применял для этого экзистенциализм и глубинную психологию, а Барт пытался пробиться сквозь те слои идеализма и идеологии, которыми со всех сторон обросло полученное нами Евангелие, и открыть подлинное Слово Бога. Как же наше суждение о стиле секулярного человека соотносится с тем, что они делали?» [2, с. 90]. Особое место в исследовании Х.Кокса занимает полемика между К.Бартом и П.Тиллихом. С точки зрения Х.Кокса, П.Тиллих был великим пионером в области теологического анализа культуры. Он создал и отработал некоторые методы, используемые в этой книге. Несомненно, однако, что предложенные выше рассуждения и выводы серьезно ставят под вопрос теологический метод Тиллиха. Подход Тиллиха не оставляет места для прагматика. Тиллих исходит из того, что человек по самой своей природе должен задавать эти «последние», или экзистенциальные, вопросы. Конечно, Тиллих признает, что такие вопросы по-разному формулируются в разные эпохи. Человек I века спрашивал о смерти и бессмертии, человек XVI века - о вине и наказании, человека XX века тревожит угроза утраты смысла. Но сам вопрос, как утверждает Тиллих, задается всегда, и за каждой из этих формулировок скрывается одно и то же основополагающее устремление - «предельная охваченность». Тиллих считает, что мы должны выявить и вывести 
на сознательный уровень эту предельную захваченность: ведь она порождает самый вопрос, ответом на который служит Евангелие [2, с. 91].

Секулярный человек, - пишет Х.Кокс, никогда не переживал утрату невинности, хотя бы потому, что он никогда не был невинным. Он не переживал жестокого потрясения, обнаружив, что те смыслы, которые он считал созданными Богом или по крайней мере содержащимися в природе вещей, на самом деле придуманы человеком и поддаются замене. Он никогда не видел в мире никакого встроенного смысла и не понимает, почему Тиллих постоянно озабочен возможной «утратой смысла». Так же и «Бог-над-Богом» Тиллиха, который появляется (как он говорит в «Мужестве быть»), когда традиционный Бог теизма «исчезает в тревоге сомнения», — этот «Бог-над-Богом» секулярному человеку никак не может явиться, прежде всего потому, что для этого человека традиционный Бог вообще никогда не существовал. Что же касается «тревоги сомнения» по поводу Бога теизма, то тут сегодняшний человек испытывает в лучшем случае некоторое любопытство или, самое большее, что-то вроде сожаления. На большее он не способен. Секулярный человек попал в город уже после того, как религиозная картина мира была похоронена. У него нет ощущения утраты, и ему нечего оплакивать [2, c.91-92].

Х.Кокс отмечает, что как и философский экзистенциализм, так и теология П. Тиллиха - порождения этого периода утрат, который начался смертью Бога метафизического теизма и западной христианской цивилизации. Мыслитель пишет: «Именно поэтому экзистенциалистские теологии и философии непричастны к духу рождающейся эпохи и скорее символизируют закат старой. Есть некоторая доля правды в утверждении марксистов о том, что экзистенциализм «симптом упадка буржуазного общества», ибо экзистенциалистские категории «тревога» и «тошнота» становятся все более чуждыми этосу новой эпохи. $\mathrm{B}$ эпоху мирского града нас больше всего занимают вопросы функционального и операционного характера. Мы задумываемся о том, как контролировать власть и ответственно ею пользоваться. Мы спрашиваем себя о том, каким путем на основе того технологического сообщества, в котором мы так быстро оказались, можно построить разумный международный порядок. Нас заботит возможность максимально использовать достижения медицины, но так, чтобы при этом рост населения не ставил мир перед постоянной угрозой голода. Все это - прагматические вопросы, а сами мы прагматики, и интерес к религии занимает в нашей жизни в лучшем случае незначительное место» [2, с.92].

Осмысление учения П.Тиллиха занимает особое место в контексте современных дискуссий, посвященных вопросам биоэтики и современной медицины. Д.Стел акцентирует внимание на том, что П.Тиллих, в отличие от протестантских биоэтиков, например, Д.Флетчера, своё этическое учение основывал на метафизической онтологии, а в качестве главной задачи усматривал усматривал изучение Безусловного и его пути в культуре [13, с.15]. Исследователь обращает внимание на то, что, будучи и теологом и метафизиком, П.Тиллих работал в теоретической и практической сферах. По этой причине, заключает Д.Стел, метафизика П.Тиллиха не может рассматриваться отдельно от этики $[13$, c.15].

Особой значимости в контексте исследования данного дискурса приобретает статья Д.Тетеменила «Тиллих и постмодерн». Исследователь пишет: «Для постмодернистов Тиллих слишком онтотеологичен и слишком укоренен в немецком идеализме, чтобы быть современным» [14, с.288]. Для постлибералов П.Тиллих является архмодернистом, мыслителем, чья методология утрачивает теологическую независимость, целостность и авторитет, подчиняя свои положения внешним авторитетам и критериям. С точки зрения Д.Тетеменила, П.Тиллих не являлся постмодернистским теологом. Учение 
«Філософія та політологія в контексті сучасної культури», 2018, Т.10. №1-2 (22)

П.Тиллиха, как считает исследователь, предполагает поствестернизм и знаменует собой важный шаг, преодолевающий культурные рамки, установленные Просвещением. Исходя из этого, считает автор, посмодернистским теологам еще предстоит узнать П.Тиллиха [14, с. 301].

Учение П.Тиллиха занимает важное место в свете экуменического и межрелигиозного диалога. Х.Данц отмечает, что чрезвычайное значение в контексте этого диалога имеют прочитанные П.Тиллихом Бамптонские лекции, более известные как «Христианство и встреча мировых религий», а также статья «Значение истории религий для теолога систематика». П.Тиллих систематизировал свои взгляды в формуле «теология истории религий»-программе,воспринятойвГермании в первую очередь Э.Бенцом и В.Паннебергом. Тиллиховские разработки в области теологии истории религии, показывает Х.Данц, позволяют проводить соотнесение различных религиозных традиций. Теоретико-религиозным основанием указанной теологии религий выступает первая часть тиллиховской статьи. Именно мыслителю принадлежит выдающийся вклад в сферу взаимоотношения между христианством и нехристианскими религиями [6, с.11]. Тиллиховская программа религиозно-исторической теологии, заключает Х.Данц, призвана служить лучшему пониманию нашей собственной религии в горизонте истории религий. Такое восприятие (столь чувствительного к различиям) отношений между христианством и нехристианских религий обеспечивает настоящую альтернативу в дискуссиях о теологии религиозного плюрализма [6, с.14].

Значение учения П.Тиллиха для современной теологии не поддается сомнению. У.Хортон обращает внимание, что оно ярко проявилось в континентальной протестантской теологии, американской протестантской теологии и по отношению к католической теологии. В континентальной теологии, обращает внимание исследователь, учение П.Тиллиха находилось в тесном сотрудничестве с неоортодоксией К.Барта [8, c. 34].

Рецепция учения П.Тиллиха особо ярко проявилась в феминистической теологии. Как обращает внимание Р.С. Баард, представители теологии феминизма часто возражают против абстрактного характера теологии П.Тиллиха и андроцентристских аспектов его мысли. Однако, как показывает исследователь, существует особая признательность к курсу П.Тиллиха со стороны феминистских богословов - М.Дейли, Д.Пласков, С. Лихтман и М.Э. Стенгер. Именно с П.Тиллихом феминистские теологи находят значительно большее количество точек соприкосновения, нежели с богословами-мужчинами. Эти точки соприкосновения включают в себя широко используемые программы социальной справедливости, методологическию открытость человеческого опыта и в особенности онтологию [5, с.273]. Мыслителю, обращает внимание Р.С.Баард, не удалось избежать андроцентристских особенностей в своём учении и мысли, что в определенной степени не позволяет коррелироваться с символами христианства [5, с. 285].

Стоит отметить, что учение П.Тиллиха в значительной мере повлияло на апологетику Б.Рамма, нарративную теологию Дж.Струпа и Э.Райта, новую католическую теологию Г.Кюнга, теологию освобождения М.Л. Кинга, метафизику А.Уайтхеда, экзистенциальную христологию К.Ранера, теологию надежды Ю.Мольтманна и В.Панненберга.

Как показывает Т.Лифинцева, учение П.Тиллиха в значительной мере повлияло на левокатолическую «теологию освобождения» в Латинской Америке, а также на различные версии «процесс-теологии» и «контекстуальной теологии» [3, с. 246]. Безусловно, влияние П.Тиллиха, в особенности его реинтерпретация традиционных положений христианской религии - Бога, греха, Христа как Самобытия, отчуждения и Нового Бытия - была попыткой представить христианство в новом свете, учитывая достижения современной культуры. Тиллиховские попытки 
«Філософія та політологія в контексті сучасної культури», 2018, Т.10. №1-2 (22)

коннотировать христианскую традицию с экзистенциализмом, психоанализом, секулярным языком вместе с тем отражают его основной замысел - предоставить миру актуальное и релевантное христианство, затрагивающие глубинные вопросы человеческого существования и в каждую новую эпоху говорящее с человеком на его языке.

Учение П.Тиллиха в значительной степени повлияло практически на все современные философско-религиозные направления. П.Тиллих выступает одним из основателей современной философско-религиозной мысли. Его философское наследство оказало значительное влияние практически на все современные теологические учения, такие как: экзистенциальная христология (К.Ранер), новая католическая теология (Г.Кюнг), секулярная теология (Х.Кокс), нарративная теология (Дж.Струп, Е. Райт) и др.

Тиллиховское переосмысление теизма христианской традиции в значительной степени повлияло на становление секулярной теологии XX века, в частности, на учение Дж.Робинсон, Дж.Шелби-Спонга, метафизику А.Уайтхеда, «Теологии смерти Бога» Т.Альтицера и В.Гамильтона, теологию освобождения М.Л. Кинга, процесс-теологию Ч.Хартшорна. Особое значение учение П.Тиллиха занимает в контексте современных дискуссий, посвященных соотношению биоэтикии медицины, межконфессионального диалога, экуменического движения, дискурса перспектив богословской антропологии.

Отдельные аспекты тиллиховской эк $з$ истенциально-герменев тической концепции в значительной степени повлияли на теологию надежды Ю.Мольтманна и В.Панненберга, теологию феминизма М.Е.Стенгер, М.Дейли, Ю.Пласков, апологетику Б.Рамма. Влияние П.Тиллиха особенно заметно в современных философскорелигиозных течениях западной Эвропы и США. Представленная экзистенциальногерменевтическая концепция П.Тиллиха является попыткой мыслителя говорить о вечном и неизменном на языке секулярности. С этой целью П.Тиллих искал такие науки и направления, которые делали этот проект возможным. В качестве таковых П.Тиллих усматривал экзистеницализм и психоанализ.

\section{Библиографические ссылки}

1. Гренц С., Олсон Р. Богословие и богословы XX века Пер. с англ. Черкассы, 2011. Коллоквиум. 520 с.

2. Кокс Х. Мирской град: Секуляризация и урбанизация в теологическом аспекте. Пер. с англ. О.Боровой и К. Гуровской. Под общей ред. и с примеч. О.Боровой. Послесл. С. Лёзова. М., 1995. 263 с.

3. Лифинцева Т.П. Философия и теология Пауля Тиллиха / Татьяна Петровна Лифинцева. M., 2009. 287 c.

4. Armstrong K. A. History of God: From Abraham to Present: The 4,000-year Quest for God / Karen A. Armstrong. 198 p.

5. Baard R.S. Tillich and feminism. Cambridge companion to Paul Tillich edited by Russell Re Manning. Cambridge University Press, 2009. P. 273-287.

6. Danz C. Tillich's philosophy. Cambridge companion to Paul Tillich edited by Russell Re Manning. Cambridge University Press, 2009. P. 173-188.

7. Gunson J. Learning to live without God. 2005. 166 p.

8. Horton W.M.: Tillich's Role in Contemporary Theology. The Theology of Paul Tillich. New York., 1952. P. 26-49.

9. Kelsey D.H. Paul Tillich. The modern theologians: an introduction to Christian theology since 1918. 3rd ed. by Blackwell Publishing Ltd, 2005. P. 62-75. 
«Філософія та політологія в контексті сучасної культури», 2018, Т.10. №1-2 (22)

10. Mollegen A.T. Christology and Biblical Criticism in Tillich. The Theology of Paul Tillich. New York., 1952. P. 230-247.

11. Robinson J. Honest to God. The Westminster Press. SCM PRESS LTD Philadelphia, 1963. 143 p.

12. Spong J.S. A New Christianity for a New World: Why Traditional Faith Is Dying and How a New Faith Is Being Born. Harper San Francisco, 2001. 276 p.

13. Stahl D. Challenging the Ground of Medicine: Liberal Protestantism, Metaphysics, and a Critique of Modern Bioethics. Bulletin of the North American Paul Tillich Society, vol. 39, no. 3, Summer 2013. P. 15-17.

14. Thatamanil J. Tillich and the postmodern. Cambridge companion to Paul Tillich edited by Russell Re Manning. Cambridge University Press 2009. P. 288-302.

\section{References}

1. Grenc S., Olson R. Bogoslovie i bogoslovy XX veka. Per. s angl. Herkassy 2011. 520 s.

2. Koks H. Mirskoj grad: Sekulyarizaciya i urbanizaciya v teologicheskom aspekte. Per. s angl. O.Borovoj i K. Gurovskoj. Pod obshchej red. i s primech. O.Borovoj. Poslesl. S. Lyozova. M., 1995. $263 \mathrm{~s}$.

3. Lifinceva T.P. Filosofiya i teologiya Paulya Tilliha. M., 2009. 287 s.

4. Armstrong K. A. History of God: From Abraham to Present: The 4,000-year Quest for God.198 p.

5. Baard R.S. Tillich and feminism. Cambridge companion to Paul Tillich edited by Russell Re Manning. Cambridge University Press 2009. P. 273-287.

6. Danz C. Tillich's philosophy. Cambridge companion to Paul Tillich edited by Russell Re Manning. Cambridge University Press 2009. P. 173-188.

7. Gunson J. Learning to live without God. 2005. 166 p.

8. Horton W.M.: Tillich's Role in Contemporary Theology. The Theology of Paul Tillich. New York., 1952. P. 26-49.

9. Kelsey D.H. Paul Tillich. The modern theologians: an introduction to Christian theology since 1918. 3rd ed. by Blackwell Publishing Ltd, 2005. P. 62-75.

10. Mollegen A.T. Christology and Biblical Criticism in Tillich. The Theology of Paul Tillich. New York., 1952. P. 230-247.

11. Robinson J. Honest to God. The Westminster Press. SCM PRESS LTD Philadelphia, 1963. 143 p.

12. Spong J.S. A New Christianity for a New World: Why Traditional Faith Is Dying and How a New Faith Is Being Born. Harper San Francisco, 2001. 276 p.

13. Stahl D. Challenging the Ground of Medicine: Liberal Protestantism, Metaphysics, and a Critique o f Modern Bioethics. Bulletin of the North American Paul Tillich Society, vol. 39, no. 3, Summer 2013. P. 15-17.

14. Thatamanil J. Tillich and the postmodern. Cambridge companion to Paul Tillich edited by Russell Re Manning. Cambridge University Press 2009. P. 288-302. 